\title{
$\widehat{A}$ Madridge \\ madridge Journal of Case Reports and Studies \\ Interconnecting Scientific World
}

Research Article

Open Access

\section{A Cross study of Cutaneous Tuberculosis: A still relevant Disease in Morocco (A Study of 146 Cases)}

\author{
Safae Zinoune, Hannane Baybay, Ibtissam Louizi Assenhaji, Mohammed Chaouche, Zakia Douhi, Sara Elloudi, \\ and Fatima-Zahra Mernissi \\ Department of Dermatology, University Hospital Hassan II, Fez, Morocco
}

\section{Article Info}

*Corresponding author:

Safae Zinoune

Doctor

Department of Dermatology

Hassan II University Hospital

Fès, Morocco

E-mail:dr.zinounesafae@gmail.com

Received: March 12, 2019

Accepted: March 18, 2019

Published: March 22, 2019

Citation: Zinoune S, Baybay H, Assenhaji LI, et al. A Cross study of Cutaneous Tuberculosis: A still relevant Disease in Morocco (A Study of 146 Cases). Madridge J Case Rep Stud. 2019; 3(1): 126-129.

doi: $10.18689 /$ mjcrs-1000131

Copyright: @ 2019 The Author(s). This work is licensed under a Creative Commons Attribution 4.0 International License, which permits unrestricted use, distribution, and reproduction in any medium, provided the original work is properly cited.

Published by Madridge Publishers

\begin{abstract}
Background: Burden of tuberculosis still persists in Morocco despite major advances in its treatment strategies. Cutaneous tuberculosis (CTB) is rare, and underdiagnosed, due to its clinical and histopathological polymorphism. The purpose of this multi-center retrospective study is to describe the epidemiological, clinical, histopathological and evolutionary aspects of CTB in Fez (Morocco).
\end{abstract}

Methods: We conducted a cross-sectional descriptive multicenter study from May 2006 to May 2016. The study was performed in the department of dermatology at the University Hospital Hassan II and at diagnosis centers of tuberculosis and respiratory diseases of Fez (Morocco). The patients with CTB confirmed by histological and/or biological examination were included in the study.

Results: 146 cases of CTB were identified. Men accounted for $39.8 \%$ of the cases (58 patients) and women $60.2 \%$ (88 cases), sex-ratio was $0.65(\mathrm{M} / \mathrm{W})$. The age of the patients ranged from 15 months to 92 years, with an average age of 34.7 years. The average length of follow-up was $22 \pm 10$ months. The clinical forms were dominated by tuberculosis scrofuloderma (46\%) and erythema induratum of Bazin (EIB) (20\%), followed by gummas (14\%), lupus vulgaris ( $8 \%)$, tuberculosis verrucosa cutis (4\%), papulonecrotic tuberculids (3\%), tuberculosis chancre (3\%) and orificial tuberculosis (2\%).

Conclusion: The predominance of multibacillary forms of cutaneous tuberculosis, scrofuloderma, and gummas testify to the endemicity of this disease in our country.

Keywords: Tuberculosis; Cutaneous; Mycobacterium Tuberculosis; Scrofuloderma; Erythema Induratum.

\section{Introduction}

Tuberculosis (TB) is known as a disease of poverty. The burden of TB, especially in developing countries like Morocco still remains a daunting challenge for global and national health programs. According to the WHO Global TB report 2018, the estimated incidence of TB in Morocco in 2017 was around 88/100 000 inhabitants and extrapulmonary TB (EPT) accounts for $48 \%$ of registered cases [1]. However, the cutaneous localization of the disease remains very rare. It represents $1-1.5 \%$ of all extra-pulmonary tuberculosis manifestations, which manifests only in $8.4-13.7 \%$ of all tuberculosis [2]. The diagnosis of cutaneous tuberculosis is often difficult because of the anatomoclinical polymorphism and the multiplicity of differential diagnoses. The clinical manifestations are variable and depend on the interaction of several factors including the site of infection and the host's immunity [3]. 


\section{Patients and Methods}

This is a retrospective multicenter study conducted from May 2006 to May 2016. The study was performed in the department of dermatology at the University Hospital Hassan II and at diagnosis centers of tuberculosis and respiratory diseases of Fez (Morocco). The patients with CTB confirmed by histological and/or biological examination were included in the study. Data collection was based on a questionnaire with sociodemographic, clinical, paraclinical, therapeutic and evolutionary characteristics. All our patients were classified according to Beyt's classification [4].

\section{Statistical analysis}

Data were fed to computer using statistical package for social sciences (SPPS) version 11.5 and reviewed.

\section{Results}

During 10 years, 146 patients with cutaneous TB were identified. Men accounted for $39.8 \%$ of the cases (58 patients) and women $60.2 \%$ (88 cases), sex-ratio was 0.65 (M/F). The age of the patients ranged from 15 months to 92 years, with an average age of 34.7 years. Children accounted for $10 \%$ of patients with an average age of 10.5 years and extremes of 15 months and 16 years. $88 \%$ of our patients had a low socioeconomic status. Patients from urban areas were predominant with $72 \%$ of cases (89 cases) compared to $22 \%$ from rural areas. History of personal TB was present in $4 \%$ of cases, and tuberculosis contact in $9.2 \%$. Almost all patients have been vaccinated by bacillus Calmette Guérin (BCG) (98\%). The skin lesion duration prior to diagnosis ranged from 3 to 48 months.

The identified clinical forms (Table 1 ) were dominated by tuberculosis scrofuloderma, diagnosed in 67 cases (46\%) (Figureure 1) and EIB diagnosed in 29 cases (20\%) (Figureure $2)$, followed by gummas in 21 cases (14\%) (Figureure 3), lupus vulgaris in 12 cases (8\%) (Figureure 4), Tuberculosis Verrucosa Cutis in 6 cases (4\%) (Figureure 5), papulonecrotic tuberculids in 4 cases (3\%) (Figureure 6), tuberculosis chancre in 4 cases too (3\%) and orificial tuberculosis in 3 cases (2\%).

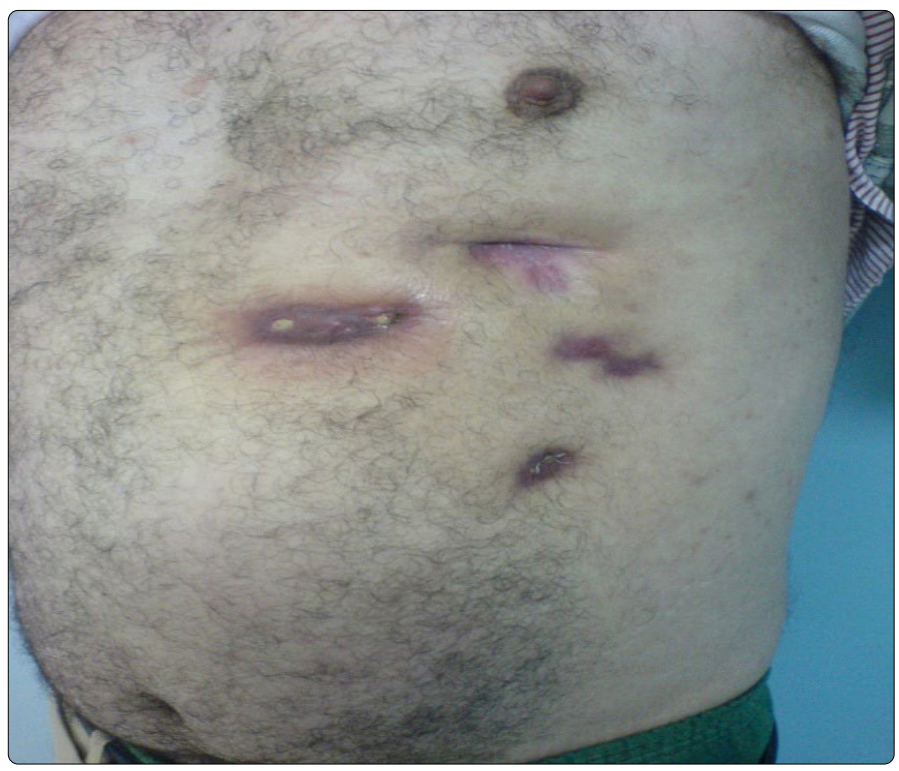

Figureure 1. Draining ulcers overlying pulmonary tuberculosis "scrofuloderma".

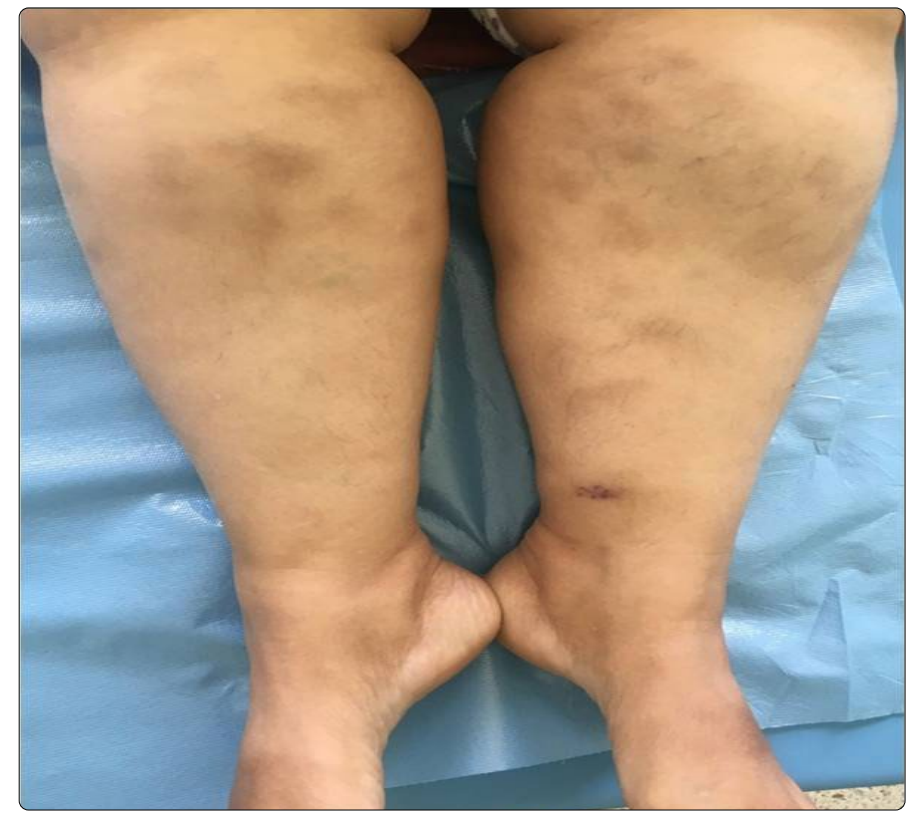

Figureure 2. Erythema induratum of Bazin.

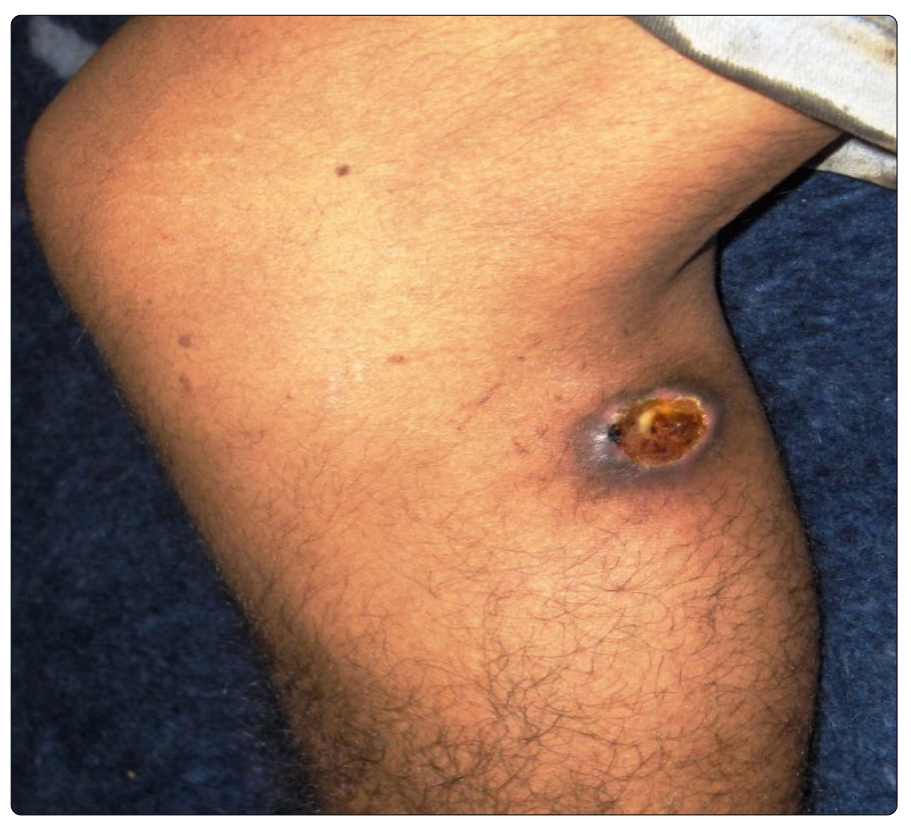

Figureure 3. Tuberculous gumma in an immunocompromised patient.

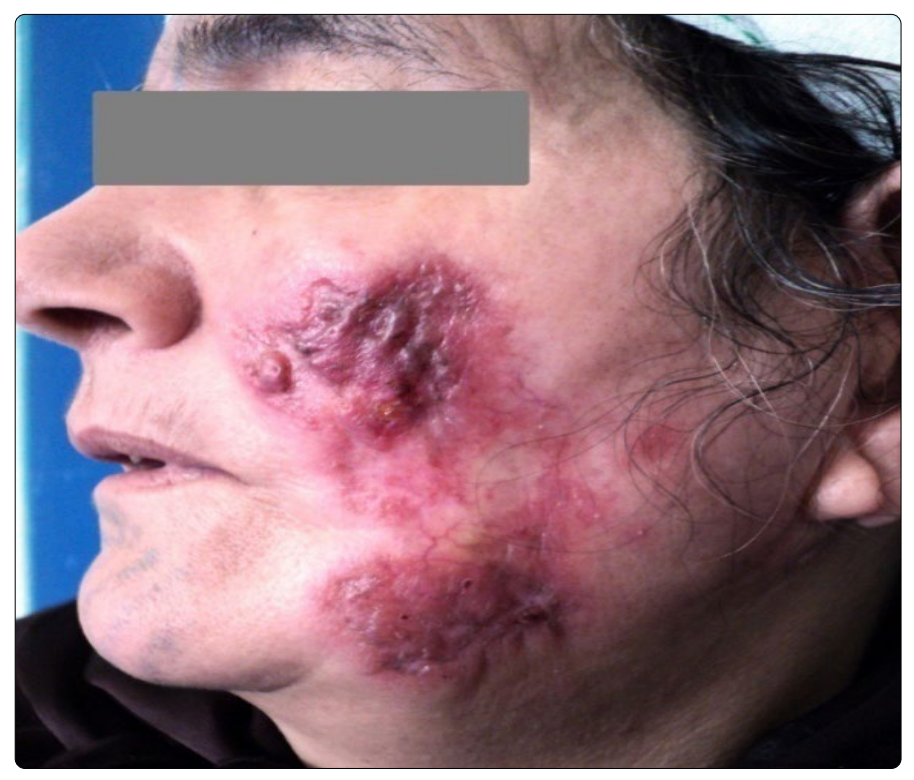

Figureure 4. Erythematous plaque of lupus vulgaris. 


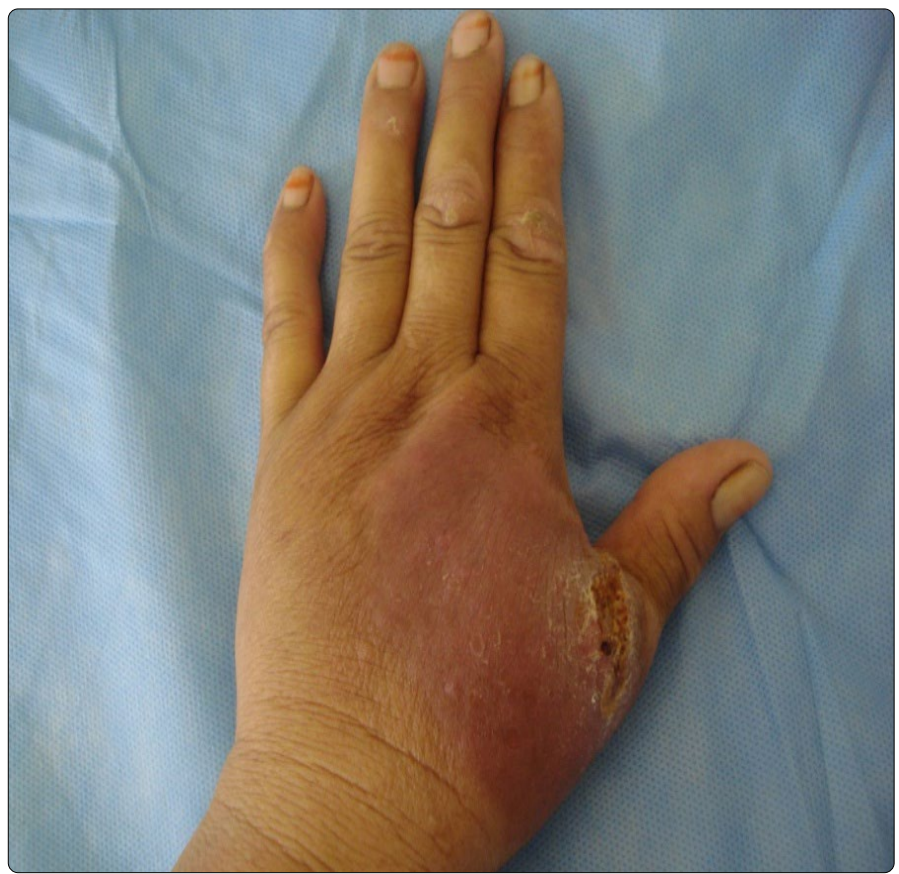

Figureure 5. Tuberculosis verrucosa (a verrucous plaque with scaling located on the left hand).

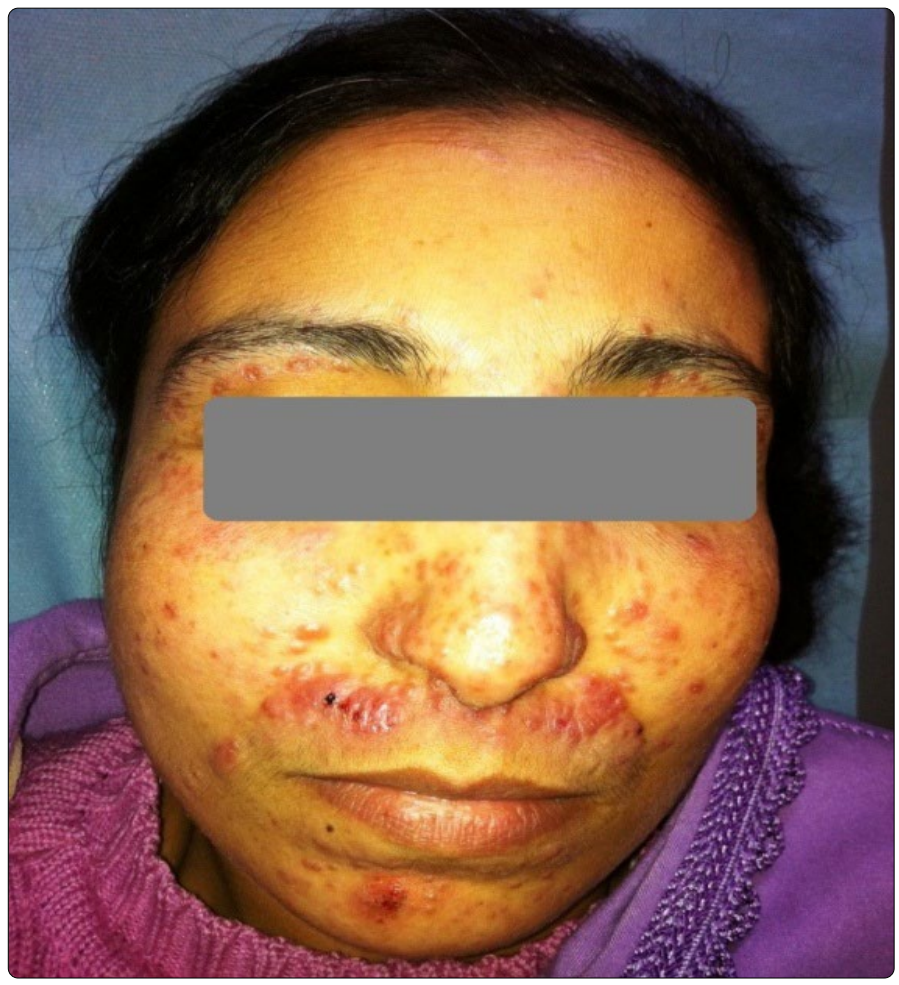

Figureure 6. Female patient whose whole facial area was implicated by papulonecrotic tuberculids.

Table 1. Clinical forms and paraclinical tests.

\begin{tabular}{|l|c|c|c|c|c|c|c|}
\hline \multirow{2}{*}{ Clinical forms } & \multirow{2}{*}{ Number } & \multicolumn{2}{|c|}{ Sex } & \multicolumn{2}{|c|}{ Tuberculin skin test } & \multicolumn{2}{|c|}{ Histology } \\
\cline { 4 - 8 } & & M & F & Done & Positive & Granuloma & $\begin{array}{l}\text { Caseous } \\
\text { necrosis }\end{array}$ \\
\hline Scrofuloderma & $67(46 \%)$ & 41 & 26 & 46 cases & 19 cases & 46 cases & 31 cases \\
\hline $\begin{array}{l}\text { Erythema induratum of } \\
\text { Bazin }\end{array}$ & $29(20 \%)$ & 0 & 29 & 29 cases & 24 cases & 29 cases & 3 cases \\
\hline Gummas & $21(14 \%)$ & 7 & 14 & 21 cases & 8 cases & 21 cases & 21 cases \\
\hline Lupus vulgaris & $12(8 \%)$ & 4 & 8 & 12 cases & 9 cases & 12 cases & 1 case \\
\hline Tuberculosis verrucosa cutis & $6(4 \%)$ & 2 & 4 & 6 cases & 5 cases & 6 cases & 4 cases \\
\hline Tuberculosis chancre & $4(3 \%)$ & 3 & 1 & 4 cases & 1 case & 4 cases & 0 \\
\hline Papulonecrotic tuberculids & $4(3 \%)$ & 1 & 3 & 4 cases & 4 cases & 4 cases & 1 case \\
\hline Orificial tuberculosis & $3(2 \%)$ & 2 & 1 & 3 cases & 0 & 3 cases & 1 case \\
\hline
\end{tabular}

The lower limb was affected in $37 \%$ of cases, the trunk in $23 \%$, the neck in $18 \%$, the upper limb in $10 \%$, the face in $8 \%$, the inguinal region, and the gluteal region in $2 \%$ each. The associated visceral localizations were found in $47.5 \%$. These were nodal locations in 46 cases, bone involvement in 12 cases, pulmonary involvement in two cases, and pericarditis in one case. Nine cases had a multifocal impairment of which one case was a child.

Regarding paraclinical tests, Tuberculin skin test (TST) reactivity was positive in $62.3 \%$ of cases. Skin specimens for Mycobacterium (M) tuberculosis culture were performed in all patients and positive results were obtained in $10 \%$ of cases. In histology, granuloma was visualized in all cases and caseous necrosis in $42.4 \%$ of cases. All our patients had a negative HIV serology and polymerase chain reaction (PCR) was performed in only two cases, one of lupus vulgaris and the other of EIB.

The treatment regimen according to the moroccan national program for the control of tuberculosis was $2 \mathrm{RHZE} / 4 \mathrm{RH}$ in $82.8 \%$ of cases (rifampicin $(\mathrm{R})$, isoniazid $(H)$, pyrazinamid $(Z)$, and ethambutol $(E)$ for two first months, then rifampicin ( $\mathrm{R})$ and isoniazid $(\mathrm{H})$ for four months), and $2 \mathrm{RHZE} / 7 \mathrm{RH}$ in rest of cases $(17,2 \%)$ (RHZE for two months then $\mathrm{RH}$ for seven months).

The outcome was favorable in all cases with total wound healing. Relapses occurred in $8.2 \%$ of cases (12 cases of EIB). Of the 12 patients who presented recurrences after treatment, two were lost to follow up. Re-treatment with antituberculous drugs was performed in 8 patients, of these, only six presented remission. Two patients needed to take other drugs (dapsone) to control resistant lesions. The average length of follow-up was $22 \pm 10$ months.

\section{Discussion}

Tuberculosis (TB) continues to draw special attention from health care professionals and society. Cutaneous tuberculosis is a rare form of extra pulmonary TB [2]. It is an infection caused by $M$. tuberculosis complex, $M$. bovis and bacillus Calmette Guérin (BCG), which depends on individual immunity, environmental factors, and type of inoculum that may present varied clinical and evolutionary aspects [5].

There are very few studies on CTB in Morocco, only three series to our knowledge [6-8]. Skin tuberculosis is most commonly seen in young adults [6-8]. In our study, the average age of patients was 34.7 years and children accounted for $10 \%$. We observed also an overall female predisposition to CTB, mainly due to a higher proportion of female patients with EIB (Table 1). Available results also indicated a female majority in EIB [9].

The relatively long duration between onset of symptoms and consultation may be explained by the slow progression of the disease, indolent nature, ignorance, illiteracy and the low economic status of most affected patients.

In our series, we find that tuberculous gumma and scrofuloderma represent $60 \%$ (87 cases). This is consistent with the moroccan series previously published where they represent $72 \%$ [6], and 66.6\% [7]. In a malian series they represented $67.2 \%$ 
[10], and in another tunisian series, they represented 84.6\% [11]. Tuberculous gumma, also known as metastatic tuberculosis abscess, is an outcome of hematogenous dissemination of mycobacteria from primary focus [12]. Scrofuloderma, also called colliquative cutis, is a common form of cutaneous tuberculosis, it results from direct extension from an underlying tuberculosis lesion in lymph node, bone, joints, or testicles $[13,14]$. The neck, axillae, and groin are often involved, with the cervical lymph nodes as a common source of infection [13]. These two clinical forms are multibacillaryand they occurespecially in an immunocompromised host, scarcely in an immunocompetent host too [13]. In developed countries, multibacillary forms are rare. They are reported mainly in patients from tuberculosis endemic countries such as african countries. These multibacillary forms are now reappearing with the emergence of HIV infection [14].

In our series, the erythema induratum of Bazin comes in the second position after scrofuloderma. The diagnosis of this form was based on the clinical aspect, the presence of granuloma on histology, the positive TST and the response to anti-bacillary treatment. Tuberculous origin has never been proven [14], however, PCR has been able to show the presence of Mycobacterium tuberculosis DNA in several cases [15,16].

In our context of endemic tuberculosis, the presence of chronic nodular hypodermitis in the lower limbs, the positive TST, and the presence of tuberculous granuloma in histology justify antibacillary treatment that in most cases gives good results [9].

Almost all of the investigative methods confer lesser sensitivity and specificities for cutaneous tuberculosis. The genotyping techniques, nevertheless, could be an assistant to cope with this diagnostic challenge, paradoxically beyond reach to the third world like ours, due to expensive running cost and wanting equipped laboratory setup. In this perspective, the clinicians must resort to every possible test, so that supporting positive rudiments would be ancillary in the early and precise diagnosis of cutaneous tuberculosis.

Regarding the treatment, it's well-established associating quadric therapy for 2 months followed by biotherapy for 4 months on average [17]. The duration of treatment for scrofuloderma and gumma depends on the duration of treatment of the underlying focus [11]. The response to treatment was good, the cure has achieved almost all cases even if scars are frequently observed.

\section{Conclusion}

Cutaneous tuberculosis is still a common problem in Morocco. Due to diverse clinical presentations of CTB, it's usually misdiagnosed or neglected, even by dermatologists.

The diagnosis is therefore based on a set of clinical, paraclinical and therapeutic arguments, but only the positivity of the culture allows a certain diagnosis. This positivity has never been found in the EIB, making its link to TB more uncertain. The place of the new diagnostic tools, as well as a more precise anatomo-clinical definition of EIB, remains to be defined.

\section{References}

1. WHO. Global Tuberculosis Report 2018. World Health Organization. 2018.

2. van Zyl L, du Plessis J, Viljoen J. Cutaneous tuberculosis overview and current treatment regimens. Tuberculosis (Edinb). 2015; 95(6): 629-638. doi: 10.1016/j.tube.2014.12.006

3. Santos JB, Figureueiredo $A R$, Ferraz $C E$, Oliveira $M H$, Silva $P G$, Medeiros VL. Cutaneous tuberculosis: epidemiologic, etiopathogenic and clinical aspects - Part I. An Bras Dermatol. 2014; 89(2): 219-228.

4. Beyt BE Jr, Ortbals DW, Santa Cruz DJ, Kobayashi GS, Eisen AZ, Medoff G. Cutaneous mycobacteriosis: analysis of 34 cases with a new classification of the disease. Medicine (Baltimore). 1981; 60(2): 95-109.

5. Dias MF, Bernardes Filho F, Quaresma MV, Nascimento LV, Nery JA, Azulay DR. Update on cutaneous tuberculosis. An Bras Dermatol. 2014; 89(6): 925-938.

6. Zouhair K, Akhdari N, Nejjam F, Ouazzani T, Lakhdar H. Cutaneous tuberculosis in Morocco. Int J Infect Dis. 2007; 11: 209-212. doi: 10.1016/j. ijid.2006.02.009

7. Gallouj S, Harmouch T, Karkos FZ, et al. [Cutaneous tuberculosis: a 36case series from Morocco]. Med Trop (Mars). 2011; 71: 58-60.

8. Akhdari N, Zouhair K, Habibeddine S, Lakhdar H. Childhood cutaneous tuberculosis from Morocco: a study of 30 cases. Pediatric Archives. 2006; 13(8): 1098-1101. doi: 10.1016/j.arcped.2006.03.150

9. Nasreddin FZ, Chiheb S, Benchikhi H. Bazin erythema indurated: efficacy of antibacillaries. Ann Dermatol Venereol. 2014; 141: S448.

10. Dicko A, Faye O, Fofana Y, et al. Cutaneous tuberculosis in Bamako, Mali. Pan Afr Med J. 2017; 27: 102. doi: 10.11604/pamj.2017.27.102.11577

11. Abdelmalek R, Mebazaa A, Berriche A, et al. Cutaneous tuberculosis in Tunisia. Med Mal Infect. 2013; 43(9): 374-378. doi: 10.1016/j. medmal.2013.06.017

12. Abebe F, Bjune $G$. The Protective role of antibody responses during Mycobacterium tuberculosis infection. Clin Exp Immunol. 2009; 157(2): 235-243. doi: 10.1111/j.1365-2249.2009.03967.x

13. Almagro M, Del Pozo J, Rodríguez-Lozano J, Silva JG, Yebra-Pimentel MT, Fonseca E. Metastatic tuberculous abscesses in an immunocompetent patient. Clin Exp Dermatol. 2005; 30(3): 247-249.

14. Bilan $P$, Sin C, Wann A-R, et al. Tuberculosis of the skin and Bazin erythema induratum: a retrospective study of 13 cases. Ann Dermatol Venereol. 2015; 142(4): 237-244. doi: 10.1016/j.annder.2015.01.015

15. Cribier B, Grosshans E. [Bazin's erythema induratum: obsolete concept and terminology]. Ann Dermatol Venereol. 1990; 117(12): 937-943.

16. Tigoulet $F$, Fournier $V$, Caumes $E$. [Clinical forms of the cutaneous tuberculosis]. Bull Soc Pathol Exot. 2003; 96(5): 362-367.

17. Santos JB, Figureueiredo AR, Ferraz CE, Oliveira MH, Silva PG, Medeiros VL. Cutaneous tuberculosis: diagnosis, histopathology and treatment Part II. An Bras Dermatol. 2014; 89(4): 545-555. doi: 10.1590/abd18064841.2014274 